\title{
SIMULTANEOUS AND CONVERSE APPROXIMATION THEOREMS IN WEIGHTED LEBESGUE SPACES
}

\author{
YUNUS E. YILDIRIR AND DANIYAL M. ISRAFILOV
}

Abstract. In this paper we deal with the simultaneous and converse approximation by trigonometric polynomials of the functions in the Lebesgue spaces with weights satisfying so called Muckenhoupt's $A_{p}$ condition.

Mathematics subject classification (2010): 41A10, 42A10.

Keywords and phrases: Best approximation,weighted Lebesgue space, mean modulus of smoothness, fractional derivative.

\section{REFERENCES}

[1] R. AkgÜN AND D. M. IsRafILov, Approximation in weighted Orlicz spaces, accepted for publication in Mathematica Slovaca.

[2] P. L. Butzer, H. Dyckhoff, E. Görlich And R. L. Stens, Best trigonometric approximation, fractional order derivatives and Lipschitz classes, Can. J. Math., 29, 3 (1977), 781-793.

[3] J. CZIPSZER AND G. FREUd, Sur l'approximation d'une fonktion périodique et de ses dérivées succesives par un polynome trigonometrique et par ses dérivées succesives, Acta Math., 99 (1958), 33-51.

[4] Z. Ditzian, V. Totik, Moduli of Smoothness, Springer Ser. Comput. Math. 9, Springer, New York, 1987.

[5] E. A. HACIYEVA, Investigation of the properties of functions with quasimonotone Fourier coefficients in generalized Nikolskii-Besov spaces, (in Russian), Author's summary of candidate dissertation, Tbilisi, 1986.

[6] R. Hunt, B. Muckenhoupt And R. Wheeden, Weighted norm inequalities for the conjugate function and Hilbert transform, Trans. Amer. Math. Soc., 176 (1973), 227-251.

[7] V. M. Kokilashvili, Y. E. YildiriR, On the approximation in weighted Lebesgue spaces, Proceedings of A. Razmadze Math. Inst., 143 (2007), 103-113.

[8] D. S. KURTZ, Littlewood-Paley and multiplier theorems on weighted $L^{p}$ spaces, Trans. AMS, 259, 1 (1980), 235-254.

[9] N. X. KY, Moduli of mean smoothness and approximation with $A_{p}$-weights, Annales Univ. Sci. Budapest, 40 (1997), 37-48.

[10] An Alexits's lemma and its applications in approximation theory. Functions, Series, Operators, L. Leindler, F.Schipp, J. Szabados (eds.), Budapest, 2002, 287-296.

[11] A. Marchaud, Sur les dérivées et sur les differences des fonctionsde variables réelles, J. Math. Pures appl., 6 (1927), 337-425.

[12] G. Mastroianni And V. Totik, Weighted polynomial inequalities with doubling and $A_{\infty}$ weights, Constr. Approx., 16 (2000), 37-71.

[13] B. MucKenhoupt, Weighted Norm Inequalities for the Hardy Maximal Function, Transactions of the American Mathematical Society, 165, 1972, 207-226.

[14] S. G. Samko, A. A. Kilbas, And O. I. Marichev, Fractional integrals and derivatives. Theory and applications, Gordon and Breach Science Publishers, 1993.

[15] S. B. Steckin, On the order of the best approximations of continuous functions, Izv. Akad. Nauk SSSR Ser. Mat., 15 (1951), 219-242.

[16] R. TABERSKI, Differences, moduli and derivatives of fractional orders, Comment. Math., 19 (1977), $389-400$. 
[17] Two indirect approximation theorems, Demonstratio Mathematica, 9, 2 (1976), 243-255.

[18] A. F. Timan, Investigation in the theory of approximation of functions, Dissertation, Khar'kov, 1951.

[19] Theory of appoximation of functions of a real variable, Pergamon Press and MacMillan, 1963; Russian original published by Fizmatzig, Moscow, 1960. 